\title{
Divulgación de las ciencias: Richard Feynman, Stephen Hawking y Jorge Wagensberg
}

\author{
Josep María Fernández Novelle ${ }^{a}$, Carme Zaragoza Domenech ${ }^{b}$ \\ ${ }^{a}$ Universidad de Barcelona,Departamento de Bioquímica y Biología Molecular, España, \\ ¡mfernandeznovell@ub.edu; ${ }^{\mathrm{b}}$ Institu Obert de Catalunya, IOC. Barcelona, España, \\ carme.zaragoza.domenech@gmail.com.
}

\begin{abstract}
Este año 2018 se celebra el centenario del nacimiento de Richard Feynman $y$, por desgracia, la pérdida de dos científicos y divulgadores excepcionales, Stephen Hawking y Jorge Wagensberg. La divulgación de la ciencia es hacer accesible a toda la sociedad los descubrimientos cientificos, anteriores y actuales. Por ello, se han propuesto una serie de trabajos y charlas, sobre estos tres científicos, al alumnado de cièncias de diversos centros de Enseñanza Secundaria de Barcelona y, también, a nuestro alumnado universitario. El resultado ha sido muy positivo y muestra que el alumnado de los distintos centros educativos, públicos y privados, ha obtenido una visión más real de dichos científicos y de la importante tarea que desarrollaron con la difusión de la ciencia. Esta innovación educativa es adaptable a todos los niveles desde primaria hasta el alumnado universitario de primer año.
\end{abstract}

Keywords: Cientificos, difusión de la ciencia, educación Secundaria, Universidad.

\section{Introducción}

La divulgación de la ciencia es hacer accesible a toda la sociedad los descubrimientos científicos, anteriores y actuales. En nuestros dias, la divulgación científica se realiza en muchos formatos diferentes, en documentales de televisión como "El Cosmos: un viaje personal" de Carl Sagan [1] o "Redes" de Eduard Punset [2]; en revistas de divulgación científica como "Muy Interesante" o "National Geographic" o "Investigación y ciencia"; mediante artículos sobre los avances de la medicina y las ciencias en periódicos generalistas como "The Guardian", "La Vanguardia", "El Punt Avui" y otros, finalmente, en páginas de Internet como "Nationalgeographic.com" o "CatQuímica.cat" entre otras. Existen incluso 
canales de televisión dedicados exclusivamente a la divulgación científica o en los que esta nueva disciplina forma una parte destacada de la programación, tales como Discovery Channel o National Geographic Channel. Algunos libros sobre divulgación cinetífica han llegado a convertirse en auténticos best-sellers, como "Cosmos" de Carl Sagan, "Historia del tiempo" de Stephen Hawking, "El gen egoista" de Richard Dawkins o "La doble hélice" de James D. Watson (2011). En este último apartado no se puede olvidar a Isaac Asimov, autor de ciencia ficción, una forma de divulgación científica, con obras como "La Fundación", "Yo robot" o "El fin de la eternidad" pero Asimov también escribió sobre divulgación científica oficial, así en "Breve historia de la química", "100 preguntas básicas sobre la ciencia" o "Historia y cronología de la ciencia y los descubrimientros" explica los conceptos científicos de una forma de fácil comprensión para todo el mundo y siguiendo la historia de los acontecimientos.

Este año 2018 se celebra el centenario del nacimiento de Richard Feynman y, por desgracia, la pérdida de dos científicos y divulgadores excepcionales, el británico Stephen Hawking y el catalán Jorge Wagensberg.

Richard Feynman fue un apasionado divulgador de la física. Esta pasión le llevó a realizar libros, conferencias y charlas. Las más destacadas son, la primera charla sobre nanotecnología en 1959, cuando nuestro actual alumnado de universidad todavía no había nacido ni quizás sus padres. Importantes sus conferencias sobre física, "The Feynman Lectures on Physics" o sus libros traducidos "¿Está usted de broma Sr. Feynman?" o "¿Qué importa lo que piensen los demás?"

Stephen Hawking fue autor de libros divulgativos sobre ciencia sobre la cosmología en general y en los que incluso discute sobre sus propias teorías. Destacan "Breve historia del tiempo: del Big Bang a los agujeros negros" de 1988, "El Universo en una cáscara de nuez" del 2001 o "Brevísima historia del tiempo" de 2005. De todos es sabido que padecía una enfermedad neuromotora, invalidante con el tiempo, relacionada con la esclerosis lateral amiotrófica (ELA) desde los 21 años.

Jorge Wagensberg fue un divulgador científico que fue profesor en la Facultad de Física de la Universidad de Barcelona y destacó como editor, conferenciante, escritor y, también, como museólogo. Creó y dirigió el Museo de la Ciencia de la Fundación "La Caixa" en Barcelona, liderando también la renovación del mismo que culminó en el, actualmente llamado, CosmoCaixa. Este museo tiene también sede en Madrid.

Estos tres científicos y divulgadores han enseñado a sus alumnos y a la sociedad en general que sin el trabajo diario y sin la disciplina necesaria para realizar dicho trabajo, el talento se apaga. Para que nuestros jóvenes aprecien más la ciencia, a dichos científicos y a su trabajo se han preparado tres presentaciones, una para cada uno de ellos, con una serie de afirmaciones o pensamientos atribuibles a de dichos científicos (aparecen en cursiva en el 
texto). Además de una serie de preguntas que el alumnado, de diferentes niveles educativos a los que va dirigida cada presentación, debería cuestionarse. Con ello se consigue que el alumnado se cuestiona algunas afirmaciones, correctas o no, para luego presentar sus propias deducciones y preguntas acerca de dichos científicos.

Estas actividades han aportado, a nuestro alumnado, una visión más real sobre los científicos en general y aquellos tan importantes como estos tres. Han aprendido de su ciencia y de su vida mientras convivían con nosotros. Esta innovación educativa sobre la historia y divulgación de la física, en particular, y de las ciencias en general, se puede aplicar tanto en la educación primaria como en la secundaria y bachillerato e incluso se puede aplicar al alumnado universitario.

\section{Richard Phillips Feynman}

"Dios fue inventado para poder explicar los misterios. Dios siempre es inventado para explicar aquellas cosas que no puedes comprender". Richard Feynman [4] nació el 11 de mayo de 1918 en Nueva York.

Cursó estudios en el Instituto de Tecnología de Massachusetts y en la Universidad de Princeton. En 1942 trabajó en las primeras etapas del proyecto Manhattan, el programa de la bomba atómica de Estados Unidos, dijo que se unió al proyecto para construirla antes de que la Alemania Nazi desplegara la suya. Junto a Bethe desarrollaron la fórmula de BetheFeynman para calcular el rendimiento de una bomba de fisión. Prosiguió desarrollando este trabajo durante la II Guerra Mundial en el laboratorio científico de Los Álamos en Nuevo México. Entre 1945 y 1950 trabajó como profesor de física en la Universidad de Cornell. En 1950 enseñó en el Instituto de Tecnología de California.

Fue muy importante su conferencia titulada "There's plenty of room at the bottom" en Caltech el 12 de Diciembre del 1959. En ella dió las primeras ideas sobre la nanociencia y la nanotecnología. Éstas quedaron reflejadas en la película de ciencia-ficción del 1966 "Viaje alucinante" de Richard Fleischer [5]. En la Figura 1 puede puede verse la "nanocápsula" moviéndose por el aparato circulatorio. 


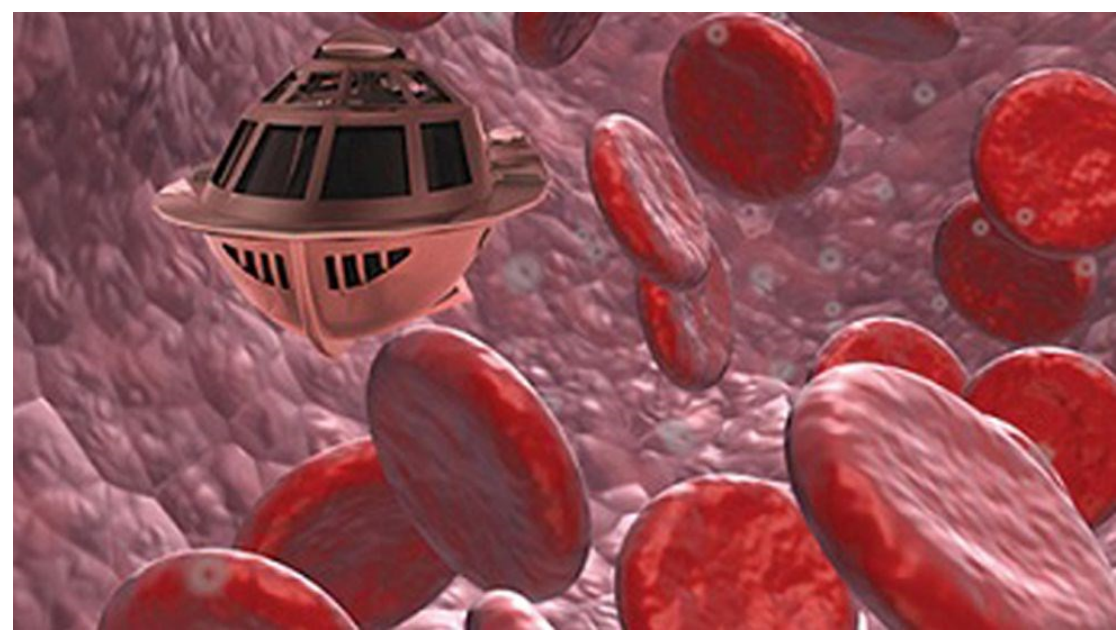

Fig. 1. Un fotograma de la película en la que los personajes reducidos de tamaño igual que la cápsula se desplazan dentro del cuerpo humano.

Donde "un científico ha creado una fórmula que permitiría reducir el cuerpo humano a un tamaño microscópico durante un tiempo ilimitado. Cuando se dispone a entregarla al Pentágono, unos espías provocan un accidente que deja al profesor incapacitado. Se une a un equipo militar y médico que abordará el submarino Proteus, el cual será reducido al tamaño microscópico y lanzado en el torrente sanguíneo del professor, con el propósito de llegar al cerebro y eliminar un coágulo que está matando al científico".

Feynman fue un divulgador entusiasta de la física, lo hizo a través de sus escritos para el público en general destacando: ¡Está usted de broma, Mr. Feynman! Aventuras de un curioso (1985) y QED: La extraña teoría de la luz y la materia (1985). También a través de los tres libros de texto que recogen todas sus conferencias de pregrado dadas en Caltech desde 1961 a 1963, las "The Feynman lectures on Physics". Éstas se encuentran repartidas entre tres volúmenes que tratan: el primero sobre la mecánica, la radiación y el calor; el segundo versa sobre el electromagnetismo y la materia; mientras que el tercero explica la mecánica cuántica.

En 1965 le otorgaron el Premio Nobel de Física, que compartió con otros dos físicos, el estadounidense Julian S. Schwinger y el japonés Shin'ichiro Tomonaga. Fue nominado por su investigación sobre la transformación de un fotón en un electrón y en un positrón (diagramas de Feynman), y el descubrimiento de un método para medir los cambios producidos en la carga y en la masa. En la Figura 2 se observa uno de dichos diagramas i su aparición/discusión en un programa de TV. 

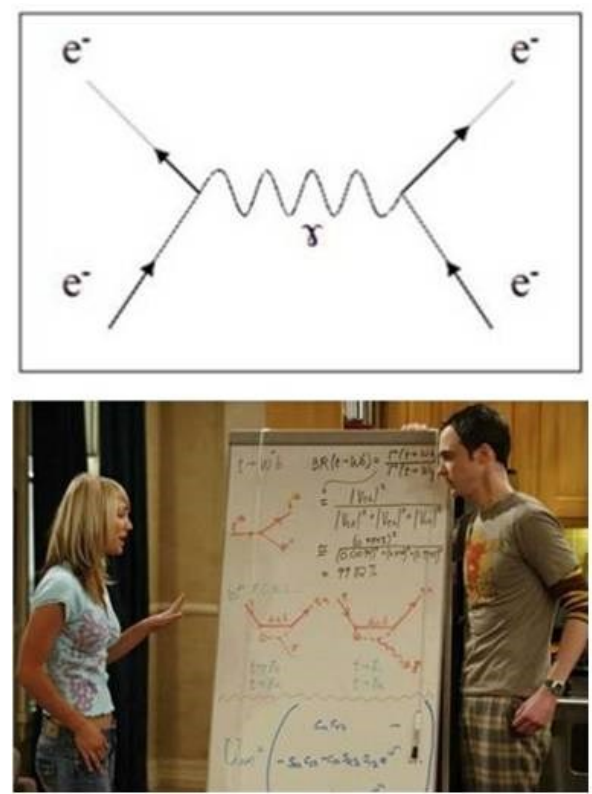

Fig. 2. Diagramas de Feynman que aparecieron en la serie "The Big Bang Theory"

Desempeñó un papel relevante en la comisión presidencial que investigó la explosión de la lanzadera espacial Challenger en 1986. Durante una audiencia televisada, Feynman demostró que el material utilizado en las juntas tóricas de la nave se vuelve menos resistente en climas fríos. Lo demostró delante de los televidentes al estudiar la compresión de una muestra del material en una abrazadera y sumergiéndolo en agua helada. La comisión, de la que Feynmam declinó la invitación, determinó en última instancia, que el desastre fue causado por la junta tórica primaria, al no haber estado sellada adecuadamente en un clima inusualmente frío en Cabo Cañaveral.

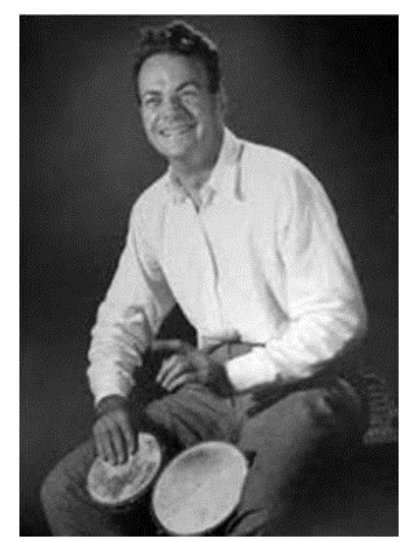

Fig. 3. Fotografia de Richard P. Feynman tocando los bongos 
$\mathrm{Su}$ forma de entender la Física, en términos simples e intuitivos, desprovista de toda sofisticación matemática innecesaria, siempre fiel al principio de que poner nombre a algo no significa entenderlo, era magnífica. Además, como se muestra en la Figura 3, fuera del ámbito científico, era conocida su afición a tocar los bongos, un ejemplo del carácter extrovertido de este físico teórico.Richard Feynman falleció en Los Ángeles, California, Estados Unidos, el 15 de febrero de 1988.

\section{Stephen William Hawking}

"Mi objetivo es simple, llegar a un entendimiento completo del Universo: ¿Por qué es?, ¿Cómo es? y ¿Por qué existe?" Stephen William Hawking nació el 8 de Enero de 1942 en Oxford, Reino Unido.

Fue un destacado físico teórico, astrofísico, cosmólogo y, importante para nosotros, un divulgador científico de excelencia. Fue un notorio miembro de la Real Sociedad de Londres y de la Academia Nacional de Ciencias de los Estados Unidos de América, fue titular de la cátedra de matemáticas de la Universidad de Cambridge desde 1979 hasta su jubilación en el año 2009.

En el trabajo con este científico se estudiarán los tres ámbitos más sobresalientes, el científico, el personal y el divulgativo. Cada uno de ellos va acompañado de unas frases del propio Hawking que iluminan su trayectoria.

Obtuvo 12 doctorados "Honoris causa", la Orden del Imperio Británico, la Medalla Coplay y muchos otros reconocimientos. (Dejamos que sea nuestro propio alumnado el que descubra el resto de su biografía científica). Si Hawking es comparable a Einstein por su popularidad e intelecto, también lo es por plantearse el ambicioso proyecto/objetivo de harmonizar la relatividad general y la mecánica cuántica. Hawking junto a Roger Penrose demostraron como la teoría general de la relatividad de Einstein implicaba que el espacio y el tiempo deben tener un principio en el Big Bang y un final en los agujeros negros.

- "Limitar la atención a cuestiones terrestres sería limitar el espiritu humano. El mayor enemigo del conocimiento no es la ignorancia, sinó la ilusión del conocimiento."

- $\quad$ "Uno no puede discutir con un teorema matemático. Preguntar que habia antes del Big Bang es como preguntarse que hay al Norte del Polo Norte."

En el ámbito personal, a los 21 años fue diagnosticado de una enfermedad motoneuronal degenerativa relacionada con la esclerosis lateral amiotrófica (ELA), los médicos le daban 
un poco más de un año de vida que él convirtió en 55 años. A medida que obtenía reconocimiento en todo el Mundo sus facultades físicas iban mermando, dejándolo en silla de ruedas prácticamente paralizado del todo teniéndose que comunicar mediante un sintetizador de voz robótica. Se casó dos veces y tuvo 3 hijos. En la Figura 4 se le observa como un viajero del espacio.

Generalmente se tomaba con humor provocador su infortunio

- $\quad$ "La Humanidad es tan insignificante si la comparamos con el Universo, que el hecho de ser minusválido no tiene importancia cósmica."

- "Es obvio que por mi discapacidad necesito ayuda. Pero siempre he tratado de superar las limitaciones. He viajado por todo el mundo, desde la Antártida hasta gravedad zero."

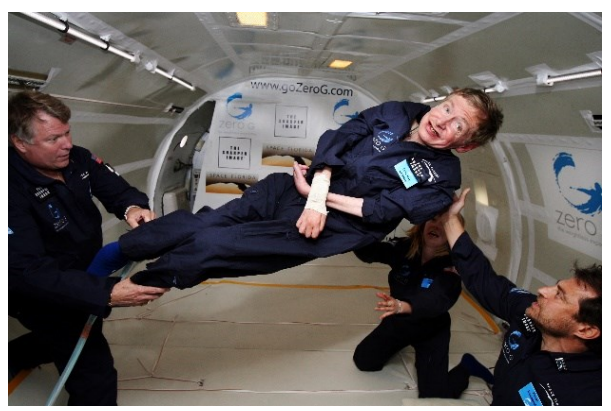

Fig. 4. El Dr. Hawking experimentando gravedad cero en un vuelo alrededor de la Tierra (Photo credit: Steve Boxall [6])

Y como divulgador, escribió numerosos libros sobre ciencia, el universo y el Big Bang que consiguieron ser best sellers, como "Breve historia del tiempo: del Big Bang a los agujeros negros" (Hawking, 1988), figura 5 (A Brief History of Time: From the Big Bang to Black Holes)", donde dijo que descubrir una teoría completa sería el triunfo definitivo de la razón humana. Otros libros de divulgación son: "El Universo en una cáscara de nuez (The Universe in a Nutshell)" del 2001, "Brevísima historia del tiempo" del 2005 o "El gran diseño (The Grand Design)" del 2010.

- "La inteligencia es la capacidad de adaptarse al cambio."

- "Solo somos una raza avanzada de simios en un planeta menor de una estrella media. Pero podemos entender el universo y esto nos hace muy especiales."

En 2007 escribió "La clave secreta del Universo" (Hawking \& Hawking, 2007) figura 5, una obra de ficción infantil. Y, finalmente, cabe mencionar algunos documentales y series como "El Universo de Stephen Hawking (Stephen Hawking's Universe)", serie que hasta hace poco tiempo se podía ver en alguno de los canales sobre ciencia. 

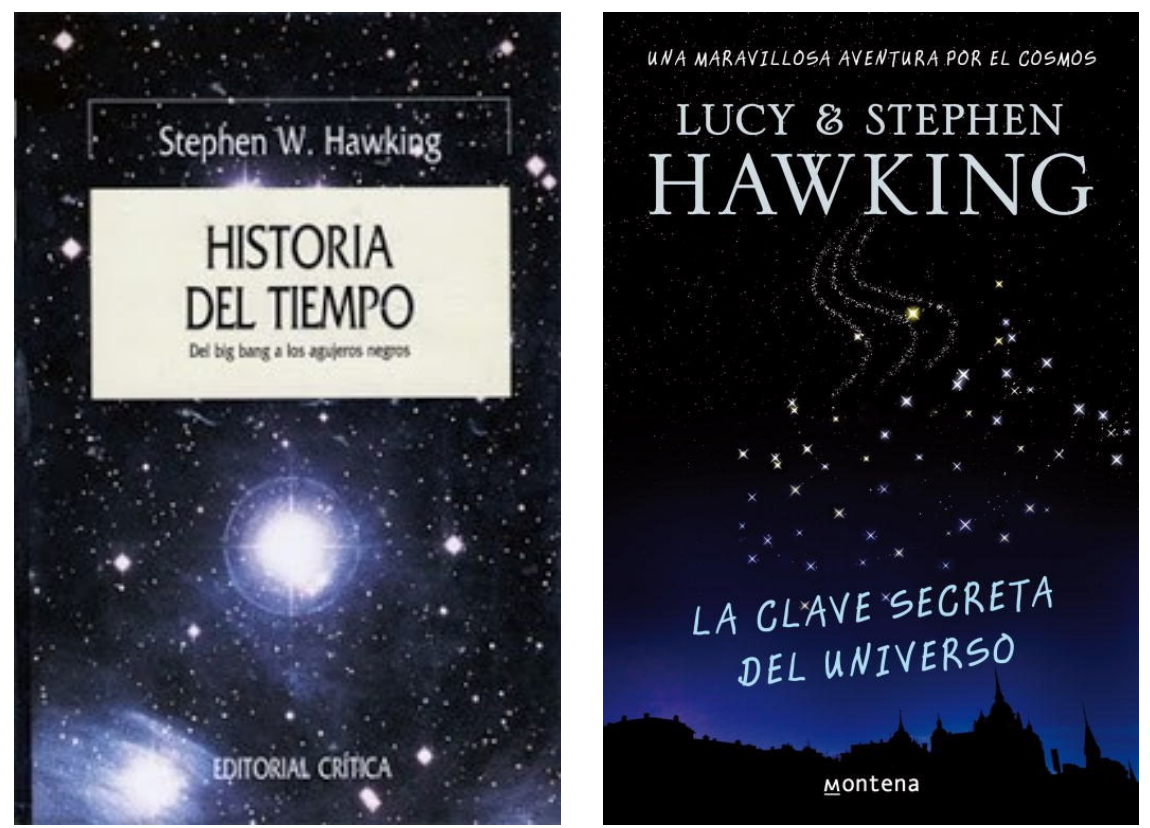

Fig. 5. Dos de los libros clave para entender la vida y la obra de Stephen Hawking, uno más científico "La historia del tiempo" y el otro más divulgativo "La Clave Secreta del Universo", especialmente dirigido para el mundo juvenil pero que sirve para explicar y aprender de forma muy elemental sobre el Cosmos y que puede entender todo el mundo, científico o no.

Descartó a Dios como creador del Universo y los seres vivos y fue muy claro a la hora de considerar incompatibles la ciencia y la religión.

- “En el pasado, era lógico creer que Dios creó el Universo. Pero ahora la ciencia ofrece una explicación más convincente. No hace falta invocar a Dios para que encienda la mecha y ponga al Universo en funcionamiento."

- “Considero que el cerebro es como un ordenador que dejará de funcionar, algún día, cuando fallen sus componentes. Por tanto, no hay ni paraíso ni vida después de la muerte, ya que tampoco la hay para los ordenadores que han dejado de funcionar. Todas estas cosas son un cuento de hadas de aquellas personas que le tienen miedo a la oscuridad."

No hay ningún Dios, soy ateo. La religión cree en los milagros, que son incompatibles con la ciencia. A pesar de sus limitaciones y discapacidad Stephen Hawking vivió hasta los 76 años, murió el 14 de marzo de 2018 en Cambridge, Reino Unido, 


\section{Jorge Wagensberg Lubinski}

"La mayoría de científicos no están formados en comunicación". Jorge Wagensberg [9] nació el 2 de Diciembre de 1948 en Barcelona. Se licenció y doctoró en Física por la Universidad de Barcelona donde fue profesor desde 1981 hasta el 2016.

Jorge Wagensberg fue uno de los más destacados divulgadores científicos de nuestro país en los últimos tiempos. Creó y dirigió el Museo de la Ciencia de la Fundación "La Caixa" [10], en Barcelona. En la Figura 6 se aprecia una imagen de dicho centro mientras que en la Figura 7 se observa un grupo de personas experimentando con la electricidad en una de las actividades propuestas en el Cosmo Caixa.

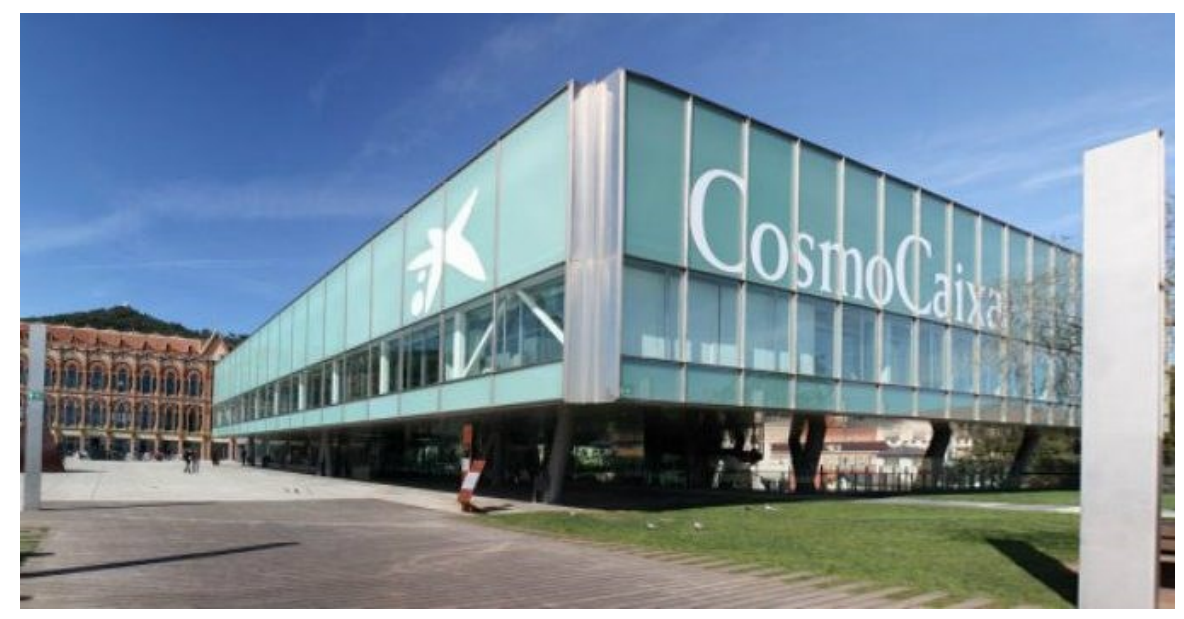

Fig. 6. Cosmo Caixa Barcelona en la actualidad

Fue el artífice de la renovación y puesta al día de los museos sobre la ciencia. Entendió que el público en general debía de ser partícipe, no un pasivo "mirón", de los experimentos que se presentaban.

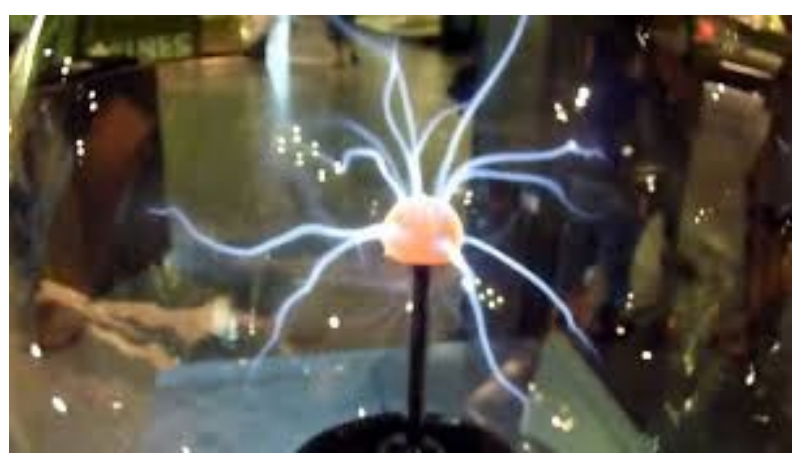

Fig. 7. Un experimento sobre electricidad estàtica con los participantes 
Aquellas personas que le conocieron, que le tuvieron como profesor o que, símplemente le escucharon en una de sus muchas y variadas conferencias, como es el caso de los autores, recordarán que siempre sacaba partido a sus metáforas.

Las metáforas se utilizan en todos los ámbitos humanos $\mathrm{y}$, también en el científico. Las metáforas son unas herramientas que utiliza la comunicación humana ya que confiere una enorme capacidad de figuración, de sugestión, de imaginación de las ideas y que sirve para persuadir, de aquellas ideas, a quien esté escuchando.

Explicaba las dudas de Darwin en plasmar como imagen, como metáfora, su teoría. Concretamente Darwin dudaba entre representar la teoría de la evolución como un diagrama arbóreo, por el que se decidió finalmente, o presentarlo como un crecimiento de coral marino. También tenía metáforas sobre el gato de Schrödinger, sobre partes del metabolismo y, los autores están casi seguros que ya había pensado en una para poder explicar el CRISPR CAS9.

Su último artículo ha sido publicado por la revista Método (Wagensberg, 2018) de la Universidad de Valencia, con el título "Vida cotidiana atrapada en el ámbar" explica, de una forma genial y divulgativa las imágenes de unos insectos atrapados en la resina de un árbol, todo ello pasaba hace más de treinta millones de años. Desde "Sálvese quien pueda" a "Sonriendo al futuro" pasando por "¿A dónde vas?" o "Afeitarse antes de comer" son títulos muy sugerentes de las imágenes que él observaba de aquellos insectos atrapados en ámbar y que quería explicar, una divulgación en toda regla.

Siempre estuvo pendiente del mundo de la enseñanza, el era un "maestro" que se preocupaba por los cambios en el currículum de ciencias. En cada cambio de Gobierno había un cambio en la política educativa, lo que ha llevado a una pérdida de credibilidad en el sistema educativo y en los propios maestros.

"Hoy hemos desprestigiado al maestro y la educación, pensando que nuestros hijos son genios por llevar nuestros genes. Haríamos bien en revalorizar el sistema educativo y a todos los maestros que nos motivan a cultivar nuestro propio talento." Jorge Wagensberg murió el 3 de Marzo del 2018.

\section{Conclusiones}

A partir de esta actividad se ha resalzado, entre nuestros estudiantes, la figura de estos tres físicos junto con sus teorías científicas. También se han discutido dichas teorías y su posible aplicación tecnológica. Además, el alumnado ha tomado consciencia de la importancia de la divulgación científica. Finalmente, ha aumentado la motivación de nuestro alumnado hacia las ciencias. 


\section{Referencias}

Buscabiografías. "Carl Sagan” Astrónomo estadounidense. (n. d.). Recuperado de https://www.buscabiografias.com/biografia/verDetalle/1868/Carl\%20Sagan [1]

Decine21. (3 Nov. 2014) "Viaje Alucinante" (Fantastic Voyage) - Trailer (VO) (n. d.) Recuperado de https://www.youtube.com/watch?v=OFPajh3gtaQ [5]

Hawking, S. (1988) Historia del tiempo: del Big Bang a los agujeros negros. Ed. Grijalbo. Barcelona. España. [7]

Hawking, L. \& Hawking, S. (2007) La clave secreta del Universo. Ed. Debolsillo. Penguin Random House Grupo Editorial. NY. EUA. [8]

"Jorge Wagensberg." (10 de Abril 2018). Wikipedia, Wikimedia Foundation. Recuperado de https://es.wikipedia.org/wiki/ Jorge_Wagensberg [9]

Obra Social "laCaixa" (n. d.) Recuperado de https://obrasociallacaixa.org/es/informacioncorporativa/cambiamos-presentes-construimos-futuros [10]

Punset, E. (16 de Mayo 2013) Redes supera los 600 programas [Blog post] Recuperado de https://www.redesparalaciencia.com/tag/blog-eduard-punset [2]

Santaolalla, J. (11 de Mayo 2018) \#5 Biografías científicas - Richard Feynman, EL GENIO. Recuperado de https://www.youtube.com/watch?v=K515rSxB8nY [4]

Steve Boxall. "Zero Gravity” (n. d.). Recuperado de http://www.steveboxall.com/zerog/ [6]

Wagensberg, J. (2018) "Vida cotidiana atrapada en ámbar (Vida quotidiana atrapada en ambre)" Métode, 97, pàg. 112. [11]

Watson, J. D. (2011) La Doble Helice: relato personal del descubrimiento de la estructura del ADN. Alianza Editorial. Madrid. España.[3] 